\title{
An Empirical Study of Pragmatic Input to Chinese EFL Learners
}

\author{
Meisong Chen ${ }^{1,3},{\mathrm{Min} \mathrm{Li}^{2} \& \text { Xinren Chen }}^{1}$ \\ ${ }^{1}$ School of Foreign Studies, Nanjing University, China \\ ${ }^{2}$ College of Foreign Languages, Nankai University, China \\ ${ }^{3}$ College of Liberal Arts, Nanjing University of Information Science \& Technology, China \\ Correspondence: Meisong Chen, School of Foreign Studies, Nanjing University, Nanjing Jiangsu, 210023, China. \\ E-mail: meisongchen2008@163.com
}

Received: August 3, $2020 \quad$ Accepted: September 10, $2020 \quad$ Online Published: September 15, 2020
doi:10.5539/ijel.v10n6p213

\begin{abstract}
Pragmatic competence has attracted increasing attention and research in SLA. Most studies, however, are product-oriented rather than input-oriented. A study of the learning targets without the support of findings from the study of the input to the learners would have no sound and reasonable basis. In view of this, we set out to explore the essentials of pragmatic input in structured or unstructured teaching contexts. An experiment was done to show whether pragmatic input to Chinese EFL learners in language teaching and learning is quantitatively and qualitatively sufficient. Findings show that the Chinese EFL learners are in great shortage of pragmatic knowledge and consequently lag behind in the development of pragmatic competence and such shortage is attributable to lack of inadequate pragmatic input. Taking into consideration the results of the present study and those yielded from related research, we propose that the pragmatic input to the learners should be enriched, contextualized and offered explicitly, and the Chinese learners of English are expected to play a more active role in acquiring necessary pragmatic input from all sources in the learning context of modern China.
\end{abstract}

Keywords: pragmatic competence, input, EFL learners, Chinese

\section{Introduction}

Regarding how FL learners acquire a second language, scholars have proposed a variety of theories. Among others, the most influential hypotheses are the Input Hypothesis, the Noticing Hypothesis, the Output Hypothesis, the L2 = L1 Hypothesis (or the Natural Order Hypothesis, the Natural Sequence Hypothesis), and the Frequency Hypothesis. These hypotheses mainly, if not exclusively, aim to tackle questions in the field of second language acquisition in general, but rarely touch upon the issue of the learner's pragmatic competence development in particular. With the switch of emphasis from grammatical competence to communicative competence in language learning, the pragmatic competence, which is an essential component of communicative competence, has attracted increasing attention and research in SLA. Scholars abroad have undertaken numerous studies on learners' pragmatic ability by examining their capacity of performing appropriate speech acts (i.e., requests, apologies, complaints, gratitude) in different contexts (Beltran-Planques \& Querol-Julian, 2018; Bergman \& Kasper, 1993; Eisenstein \& Bodman, 1993; Masaeed et al., 2018; Olshtain \& Weinbach, 1993; Sell et al., 2019; Weizman, 1993; Wong, 2010), their ability to differentiate polite from impolite speech forms (Cook, 2001), and their pragmatic awareness in comparison with their grammatical awareness (Niezgoda \& Röver, 2001). Researchers in China have also stressed the importance of developing learners' pragmatic competence, but their focus is mainly on learner's general pragmatic competence (Chen, 2009, 2014; Dong, 1994; Feng \& Wang, 2017; He \& Yan, 1986; He, 1988; Hong, 1991; Ran, 2013; Xiao \& Li, 2016; Zhou \& Shao, 2003); only a few scholars (Dai, 2019; Li \& Fan, 1998; Liu, 2015; Zhou, 2013; Zou, 2019) have explored how Chinese EFL learners perform greetings, refusals, acceptance, apologies, requests and how they give feedback signals. These studies are product-oriented analyses rather than input-oriented analyses. The objects of these studies are "the learning targets, not the learning process" (Kasper \& Rose, 2002, p. 14). A study of the learning targets without the support of findings from the study of the input to the learners would have no sound or reasonable basis. Out of this consideration, we therefore have carried out this study to explore the essentials of pragmatic input in structured or unstructured teaching contexts. By pragmatic input, we mean the provision of pragmatic knowledge or norms via teaching materials and communicative activities with a view to enable the EFL learners' meaningful 
use of language in different contexts, leading to the building up of pragmatic competence.

\section{Literature Review}

\subsection{Input Studies in China}

There have been a number of studies in China that address the input issue. Some (Ai, 1998; Dong, 2015; Liu, 2004; Shan \& Liu, 2020; Xu, 1998; Yang \& Li, 2004) have discussed the validity and implications of Krashen's Input Hypothesis. The hypothesis, which is also called the " $i+1$ " Theory or the Comprehensible Input Hypothesis, holds that "L2 acquisition takes place when learners are exposed to comprehensible input, i.e., input whose content is comprehensible to them but whose linguistic forms are slightly in advance of their current level of ability" (Ting, 2004, pp. 77-78). Other studies (Shu, 2004; Wen, 2003) argue that only comprehensible input can turn input into intake. Furthermore, Xu (1998) and Yang and Li (2004) point out that the input should have proper quantities, complexities, difficulties, and comprehensibility; otherwise, the input cannot change into intake. However, criticism on this theory argues that since neither " $i$ " nor " 1 " in " $i+1$ " can be measured, it is hard to be operationalized. Nevertheless, Ai (1988), by adopting the information theory, proposes that at least the "1" in " $\mathrm{i}+1$ " can be quantified. The " 1 " can be equal to or bigger than 0 bits, and equal to or less than 2.8 bits, that is, 0 bit $\leq 1 \leq 2.8$ bits. Therefore, the 2.8 bits is the only new comprehensible input effective for language learning.

Some scholars (Liu, 2018; Luo, 2005; Wen, 2005; Zhou, 2004) endorse the role of input frequency and have examined its effect on second language learning. N. Ellis's claim that "frequency is ... a key determinant of acquisition" (Ellis, 2002, p. 144) receives more criticism than approval. Though scholars widely acknowledge that input frequency does facilitate language learning process, they do not regard it as a key determinant. Basically, we subscribe to Ting's argument that "the input and interaction may facilitate L2 development by modeling specific grammatical patterns with a high frequency" (Ting, 2004, p. 129). Input frequency is only an external factor in language learning; it works only if the intensity, salience, and time span are reasonable. In addition, this exemplar-based theory is also hard to be operationalized.

Others also have compared the effect of input and output on SLA. While admitting the importance of input, some scholars like Zhu (2000), Xu (2002), Dong (2015) and Shan and Liu (2020) argue that output should be more emphasized in language learning and teaching. However, an experiment carried out by Sun and Wang (2003) shows that input is more important to language learning than output. In terms of input content, some scholars (Hu, 1994; Kang \& Wang, 2002; Zhu, 2000; Zhong et al., 2001) hold that cultural information should be provided in language teaching so as to avoid communicative misunderstandings or even communicative failures in practice.

Though many scholars in China have examined the input issue concerning the learning target and process and pointed out that English teaching in China lacks a pragmatic and cultural element, few of them have touched upon the issue of how pragmatic knowledge could be instructed. For this reason, the present study aims to fill this knowledge gap.

\subsection{Studies of Pragmatic Competence in China}

By definition, pragmatic competence refers to the speakers' ability to "internalize a set of rules that govern how language is used to construct discourse and to perform speech acts in socially appropriate ways" (Ellis, 1994, p. 437). Backman (1990) defines communicative language ability (CLA for short) as "both knowledge or competence and the capacity for implementing or executing that competence in appropriate, contextualized communicative language use", with pragmatic competence as one of its major components (Bachman, 1990, p. 84). Leech (1983) divides pragmatics into pragmalinguistics and sociopragmatics. The former refers to the study of such resources as pragmatic strategies like directness, indirectness, routines, and a large range of linguistic forms that are used to intensify or soften communicative acts, while the latter refers to "the social perceptions underlying participants' interpretation and performance of communicative action" (Kasper \& Rose, 2001, p. 3) such as social distance, social power, and degrees of imposition. Following Leech's criterion, we can divide pragmatic competence further into pragmalinguistic competence and sociopragmatic competence. Pragmalinguistic competence is "language-specific" (Leech, 1983, p. 11) and relates more closely to grammar; sociopragmatic competence is "culturally-specific" (ibid) and relates more closely to sociology. Admittedly, since language use is inseparable from culture, it is unreasonable to draw a clear line between pragmalinguistic and sociopragmatic competence because overlaps are unavoidable. But differentiations have to be made for the convenience of the present study. Specifically, pragmalinguistic competence, in this study, involves the speakers' or the hearers' knowledge of such linguistic resources as indexical expressions, discourse markers, modals, hedges, feedback responses, etc., while sociopragmatic competence involves the socio-cultural perspective of language use, such as greetings, compliments, refusals, and requests. This differentiation meets the "narrow 
sense of interlanguage pragmatics - the performance and acquisition of speech acts by L2 learners" (Ellis, 1994, p. 159).

Most of the syllabuses, course books and English teachers stress the importance of communicative competence because it is the ultimate goal for foreign language teaching and learning (Shu, 2004). As a major component of communicative competence, pragmatic competence has received extensive studies in China. Many scholars (He \& Yan, 1986; Hong, 1991; Wu \& Chen, 2006; Zhou \& Shao, 2003) find that Chinese EFL learners are short of pragmatic knowledge, and their pragmatic competence does not develop in step with their linguistic competence. A few others (Chen \& Li, 2015; Fan \& Li, 2001; Jiang, 2004; Li \& Fan, 1998; Liu \& Li, 1999), after examining Chinese EFL learners' acquisition of some specific speech acts, such as greetings, refusals, apologies, acceptance, and feedback, propose that pragmatic failures are much more often than linguistic errors. By exploring how Chinese EFL learners use discourse markers (or discourse particles, discourse connectives), Chen (2002), He and $\mathrm{Xu}$ (2003), Li (2004) and Li (2005) find out that Chinese EFL learners' knowledge of discourse markers is still so unsatisfactory that they may fail to employ discourse markers in speaking or writing. Taking Chinese EFL learners' low pragmatic competence into consideration, some researches (Chen \& Wang, 2012; Ran, 2016; Yang, 1995; Ran \& Yang, 2015; Shang, 1996; Ye \& Teng, 2003) propose that language teachers should promote learners' awareness of the cultural differences between China and the English speaking countries, explain to them more specific speech acts like compliments, greetings, acceptance, refusals in context, and train their ability to understand implicit meaning. As a common form of pragmatic instruction, explicit teaching is more effective in enhancing pragmatic input than implicit teaching (Chen, 2005; Tateyama, 2001).

While the insufficiency of pragmatic input for Chinese EFL learners has been detected, few researchers have discussed whether lack of adequate pragmatic input accounts for EFL learners' insufficient development of L2 pragmatic competence. By designing this study, we aim to tackle this question.

\section{Methodology}

\subsection{Research Questions}

The study aims to explore whether pragmatic input to Chinese EFL learners in language teaching and learning is quantitatively and qualitatively sufficient. In the Literature Review part, the definition, necessity and content of pragmatic competence have been examined in detail. For the experimental part of the study, the following two questions will be researched:

1) To what extent are the Chinese EFL learners pragmatically competent?

2) Is the Chinese EFL learners' insufficient pragmatic competence accountable by their lack of adequate pragmatic input?

\subsection{Subjects}

Two intact sophomore classes, each consisting of 32 Chinese college students, were randomly selected, one from the Chemical College (non-English majors), and the other from the Foreign Languages College (English majors). The basic information about the subjects participating in the study is presented below in Table 1.

Table 1. Basic information about the participants

\begin{tabular}{lllll}
\hline Subjects & \multicolumn{2}{l}{ Gender } & Average Age & Average Years of English-learning \\
\cline { 2 - 3 } & Male & Female & & \\
\hline English Majors & 7 & 25 & 20.1 & 7.4 \\
Non-English Majors & 13 & 19 & 19.8 & 7.7 \\
\hline
\end{tabular}

\subsection{Instrument}

A questionnaire consisting of 12 testing items was designed to measure whether pragmatic input to Chinese EFL learners is sufficient. Item $1,3,5,6,7$ and 10 were designed to measure the subjects' pragmalinguistic competence, while item $2,4,8,9,11$ and 12 to measure their sociopragmatic competence. In addition, the questionnaire also comprised an attitude- and experience-driven section, which aimed to reveal the subjects' opinions on and feelings about pragmatic input (For more details, see the Appendix A). The materials of these testing items were mainly adapted from He and Yan (1986), Bardovi-Harlig and Dörnyei. (1998) and Li and Fan (2002), carefully discussed and agreed upon among the authors and several other peer professionals to ensure the reliability of the questionnaire. 
Before the questionnaire was finalized, two pretests had been administered in order to ensure the content, wording and arrangement of the testing items were appropriate. The pilot study showed that all students had no obvious difficulty in understanding these items.

\subsection{Data Collection and Analysis}

The questionnaire was distributed to the subjects in a regular morning class. The subjects were told that the questionnaires were administered to them for research purposes only, and they were asked not to do any post hoc revisions. They finished all the entries within 20 minutes without having peer discussions or referring to other materials.

After the questionnaires were collected, the authors rated the subjects' responses to all the testing items in Part A, and summarized all the quantitative data from Part B. In Part A, if a subject made an appropriate judgment, 1 point would be given; otherwise, 0 point was given. If the subject could provide an additional appropriate answer, 1 more score would be given. So the total score for each testing item was 2 points, and that for the whole questionnaire 24 points. Data management and analysis were performed using SPSS 22.0 (2020). In assessing the subjects' pragmatic competence, the criteria for bad and good performance were set according to the accepted understanding as mentioned in 2.2, besides the intuitive knowledge of the authors as cultural insiders and researchers of pragmatics.

\section{Results and Discussion}

\subsection{Pragmatic Competence of Chinese EFL Learners}

Results (in Table 2) showed that on the whole Chinese EFL learners (including both English and non-English majors) got 14.14 points out of 24 points, which indicates that they made mistakes in about 42 percent of all the cases. It can also be seen from Table 2 that the students' sociopragmatic competence was much higher than their pragmalinguistic competence $($ Socio $=7.75>$ Pragma $=6.39)$. Paired-Samples T test shows that this difference has reached the significance level $(t=-4.387, d f=63$, Sig. $=.000)$. This means that the subjects' sociopragmatic competence, though also unsatisfactory, was significantly higher than their pragmatic competence. The reason is probably that since the subjects were adult speakers, some positive transfer had taken place, while negative transfer was also almost certain to happen (Bardovi-harlig, 2001; Jarvis \& Pavlenko, 2008). By contrast, the linguistic patterns concerned were mostly English-specific, and consequently positive transfer was difficult, if not unlikely.

Table 2. Subjects' general scores on every category

\begin{tabular}{llllll}
\hline & $\mathrm{N}$ & Minimum & Maximum & Mean & Std. Deviation \\
\hline Pragma & 64 & 3 & 11 & 6.39 & 1.687 \\
Socio & 64 & 2 & 12 & 7.75 & 2.116 \\
Total & 64 & 7 & 19 & 14.14 & 2.911 \\
\hline
\end{tabular}

From Table 3, it can be found that English majors engaged in the study outperformed the non-English majors in every aspect. The mean score English majors got in the questionnaire was 14.5, while that of non-English majors was 13.8. Considering the whole questionnaire consisted of 24 points, neither the English majors nor the non-English majors performed very well. The English majors could only respond to about sixty percent of the cases appropriately, and the non-English majors even a little lower than this rough percentage. Generally speaking, the subjects' sociopragmatic competence was much higher than their pragmalinguistic competence respectively $(7.8>6.7 ; 7.7>6.1)$. However, no significant differences were found in total scores as well as in scores on pragmalinguistic and sociopragmatic competence between the two groups, English majors and non-English majors.

Table 3. English and non-English majors' scores on the three categories

\begin{tabular}{llll}
\hline & Total & Pragmalinguistic & Sociopragmatic \\
\hline English Majors & 14.5 & 6.7 & 7.8 \\
Non-English Majors & 13.8 & 6.1 & 7.7 \\
Sig. & .287 & .120 & .815 \\
\hline
\end{tabular}


Figure 1 indicates that both English majors and non-English majors performed quite well on items 2, 8, especially 5, but rather poorly on items 3, 11, and 6 in particular. Besides, non-English majors performed better than English majors on items 1, 4, and 9, and as well as English majors did on items 8 and 12; in other 7 cases, they behaved worse than English majors.

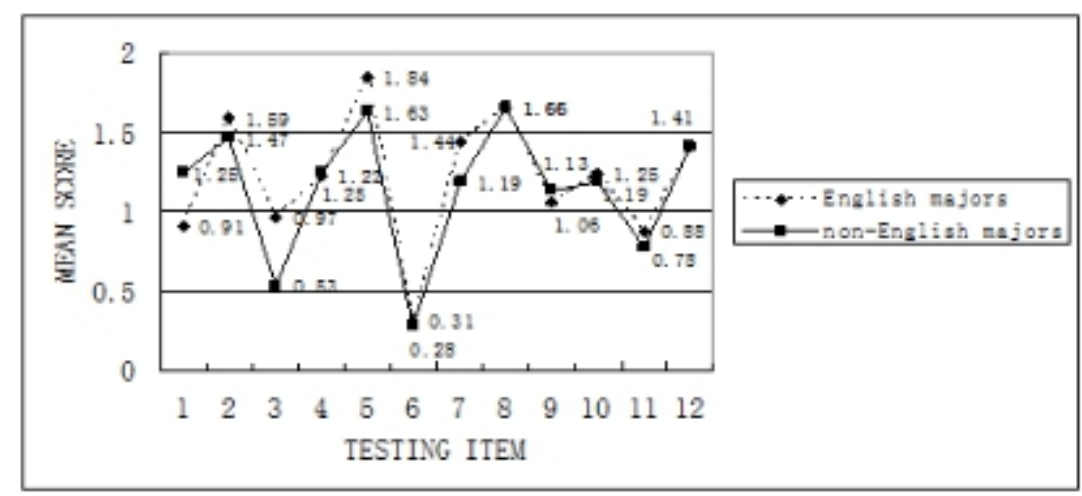

Figure 1. Comparisons of the mean scores for every item of each group

Figures 2 and 3 summarize the English and non-English majors' scores on every testing item. For English majors, more than 20 of them got the full point (2 points) on items 2, 5, 8 and 10, but more than 20 scored 0 point on item 6. In short, English majors performed especially well on item 5 but rather badly on item 6 . As for non-English majors, over 20 of them gained the full point only on items 2, 5 and 8, but more than 20 got 0 point on item 6. Non-English majors performed best on item 5 and worst on item 6 .

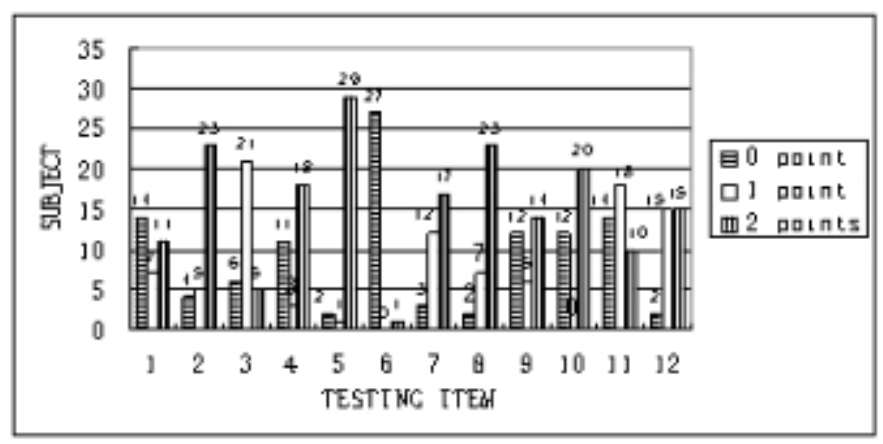

Figure 2. English majors' scores on every item

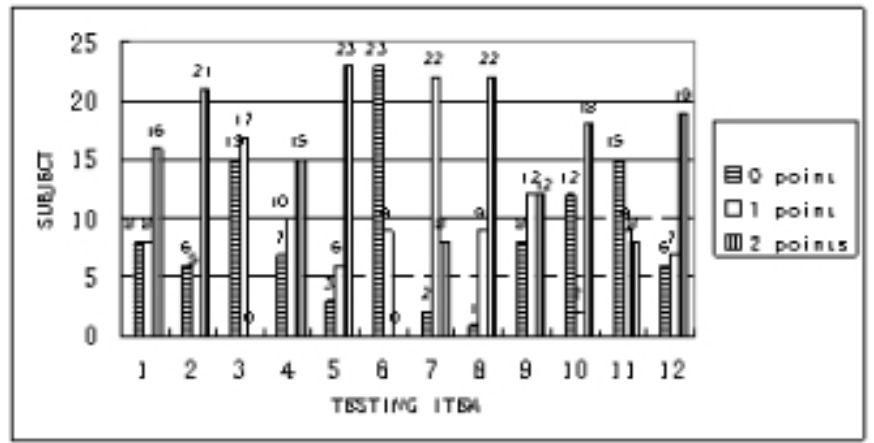

Figure 3. Non-English majors' scores on every item 
In summary, the subjects' knowledge on linguistic etiquettes was far from satisfactory and their sociopragmatic competence was significantly higher than their pragmatic competence. The English majors performed much better than non-English majors in every phase, but this difference did not reach the significance level. Both groups performed the best on item 5 and the worst on item 6 . The reason for this huge difference is that item 5 involves a distinction between the usage of "I'm sorry" and that of "Excuse me", which is presumably known to the Chinese learners from the very beginning of their English learning; however, in item 6, negative transfer is too strong to be resisted by the Chinese learners because "it doesn't matter" has been generally translated into “mei guan xi” (没关系) in Chinese, an ambiguous expression used for either apology and comfort. The appropriate response in the circumstances is "Never mind", "That's all right", and the like. In English, "It doesn't matter" means that something in question is not of critical importance. Therefore, it can be used to comfort others.

\subsection{Chinese EFL Learners' Attitudes and Reflections on Pragmatic Input}

Our analysis of the quantitative data revealed that the teachers for English majors in general provided pragmatic information for about 50 percent of the cases, while the teachers for non-English majors did so for less than 6 percent of all the cases involved in the questionnaire. Thus, it could be argued that teachers in China on the whole provided rather insufficient pragmatic instructions in class. That might be the direct explanation for why Chinese EFL learners, English majors or non-English majors alike, performed badly in the survey.

Furthermore, only 4 (about 13 percent) English majors out of the 32 had read books or articles on linguistic etiquettes, and 9 others ( 28 percent) reported they had received such information mainly from their American teachers. For non-English majors, 8 (25 percent) had paid attention to books or articles on linguistic etiquettes, but they seldom received such instructions in class. When they saw English films, over 60 percent of the English majors paid more attention to pronunciations in order to develop their own speaking and listening, about 30 percent English majors emphasized the importance of plots, and less than 10 percent were concerned about cultural differences. Speaking of the non-English majors, few of them had seen English movies; those who had only paid attention to the plots, that is, what happened in the film. Therefore, students in China seldom paid attention to exotic culture when they saw English movies. Despite this, nearly all the students (more than 98 percent) regarded the pragmatic knowledge presented in the questionnaire as necessary and essential for English study.

To conclude, English teachers in China did not provide sufficient instruction on linguistic etiquettes about communication in class, and students had little access to books, articles, or other materials on this kind of pragmatic knowledge, although most of the subjects agreed that pragmatic knowledge was crucial for English study.

\section{Conclusion}

From this study it can be concluded that owing to insufficient pragmatic input, Chinese EFL learners are in great shortage of pragmatic knowledge and consequently lag behind in the development of pragmatic competence. Comparatively speaking, their sociopragmatic competence is much higher than their pragmalinguistic competence due to probable positive transfer from their L1 pragmatic competence. In comparison of the two groups, English majors are much better than their counterparts (non-English majors) in every aspect, but the difference does not reach the significance level. It has been found that Chinese EFL learners do not have enough pragmatic instructions in class, and they have little access to this kind of knowledge outside of class, though most of them regard pragmatic competence as an essential ability for English learners.

Taking into consideration the results of the present study and those yielded from related research, the present paper proposes that the pragmatic input should be enriched, contextualized and offered explicitly, and learners of English in China are expected to play a more active role in acquiring necessary pragmatic input from all sources in the learning context of modern China.

The present study has a number of limitations that need to be overcome in future research. The discussion about the problem of inadequate pragmatic input was based on the students' reflection rather than on the researchers' classroom observation on the teachers' instruction. Moreover, future studies might investigate factors that may affect the provision of pragmatic input, so that a more comprehensive understanding of the relationship between lack of adequate pragmatic input and the pragmatic failures on the part of EFL learners could be secured.

\section{References}

Ai, R. X. (1998). i 1 ? $\leq 1 \leq$ ? Modern Foreign Languages, 80, 82-90.

Bachman, L. F. (1990). Fundamental Consideration in Language Testing. Oxford: Oxford University Press. 
Bardovi-Harlig, K. (2001). Evaluating the empirical evidence: Grounds for instruction in pragmatics? In K. Rose \& G. Kasper (Eds.), Pragmatics in Language Teaching. Cambridge: Cambridge University Press. https://doi.org/10.1017/CBO9781139524797.005

Bardovi-Harlig, K., \& Dörnyei, Z. (1998). Do language learners recognize pragmatic violations? Pragmatic versus grammatical awareness in instructed L2 learning. TESOL Quarterly, 2, 233-262. https://doi.org/10.2307/3587583

Beltran-Planques, V., \& Querol-Julian, M. (2018). English language learners' spoken interaction: What a multimodal perspective reveals about pragmatic competence. System, 74, 80-90. https://doi.org/10.1016/j.system.2018.01.008

Bergman, M. L., \& Kasper, G. (1993). Perception and performance in native and nonnative apology. In G. Kasper \& S. Blum-Kulka (Eds.), Interlanguge Pragmatics. Oxford: Oxford University Press.

Chen, C. (2005). A case study: Effects of explicit and implicit instruction on pragmatic acquisition. Nanjing: Nanjing University.

Chen, X. R. (2002). Using discourse connectives in composition: An investigation of Chinese learners' argumentative writings. Foreign Language Teaching and Research, 34, 350-354.

Chen, X. R. (2009). A New Coursebook in Pragmatics. Beijing: Foreign Language Teaching and Research Press.

Chen, X. R. (2014). A social constructionist approach to pragmatic competence. Foreign Languages Research, $8(3), 3-10,107$.

Chen, X. R., \& Li, M. (2015). Understanding pragmatic failure in the context of English as lingua franca. Foreign Languages and Their Teaching, 2, 7-12.

Cook, H. M. (2001). Why can't learners of JFL distinguish polite from impolite speech styles? In K. Rose \& G. Kasper (Eds.), Pragmatics in language teaching. Cambridge: Cambridge University Press. https://doi.org/10.1017/CBO9781139524797.009

Dai, Y. F. (2019). A Study of the Pragmatic Competence of Chinese EFL Learners in relation to Pragmatic Transfer from the Dual Language Theoretic Approach. Changchun: Northeast Normal University.

Dong, X. H. (n.d.). An investigation of the pragmatic competence of English majors of different levels. Foreign Language Education, 59, 91-95.

Eisenstein, M., \& Bodman, J. (1993). Expressing gratitude in American English. In G. Kasper \& S. Blum-Kulka (Eds.), Interlanguge Pragmatics. Oxford: Oxford University Press.

Ellis, N. (2002). Frequency effects in language processing: A review with implications for theories of implicit and explicit language acquisition. Studies of Second Language Acquisition, 24, 142-188. https://doi.org/10.1017/S0272263102002024

Ellis, R. (1994). The study of second language acquisition. Oxford: Oxford University Press.

Fan, H. Y., \& Li, Y. E. (2001). Responding Strategies of Chinese Learners in English Conversation. Foreign Languages and Their Teaching, 98, 27-29.

Feng, M. L., \& Wang, F. (2017). On the influence of college students' foreign language communicative anxiety on pragmatic and grammatical awareness. Journal of Zhejiang Ocean University (Humanities Science), 34(5), 77-82.

He, A. P., \& Xu, M. F. (2003). Small words in Chinese EFL learners' spoken English. Foreign Language Teaching and Research, 35, 446-452.

He, Z. R. (1988). A Survey of Pragmatics. Changsha: Hunan Education Press.

He, Z. R., \& Yan, Z. (1986). Chinese EFL learners pragmatic failures in English communication. Foreign Language Teaching and Research, 67, 52-57.

Hong, G. (1991). An investigation into English pragmatic competence and its implication in foreign language teaching. Foreign Language Teaching and Research, 88, 56-60.

Hu, W. Z. (1994). Culture and literature: a discussion of teaching culture through literature. Foreign Language Teaching and Research, 97, 34-38.

Jarvis, S., \& Pavlenko, A. (2008). Crosslinguistic Influence in Language and Cognition. New York, London: Routledge. https://doi.org/10.4324/9780203935927 
Jiang, Z. H. (2004). A Contrastive Study on Apology Strategies Employed by Australian University Students and Chinese University Students. Foreign Languages Research, 84, 32-35.

Kang, S. M., \& Wang, X. M. (2002). On Culture-input Model in English Teaching. Journal of Xi'an International Studies University, 10(4), 56-60.

Kasper, G., \& Rose, K. R. (2001). Pragmatics in language teaching. In K. Rose \& G. Kasper (Eds.), Pragmatics in language teaching. Cambridge: Cambridge University Press. https://doi.org/10.1017/CBO9781139524797.003

Kasper, G., \& Rose, K. (2002). Pragmatic development in a second language. Language Learning, 52(s1), 1-11. https://doi.org/10.1111/j.1467-1770.2002.tb00022.x

Leech, G. (1983). Principles of Pragmatics. London: Longman.

Li, H. (2004). On frequency-based account of SLA. Journal of Chongqing University (Social Science Edition), $10,93-96$.

Li, M. (2005). Chinese EFL learners' acquisition of the discourse marker "well”. Nanjing: Nanjing University.

Li, Y. E., \& Fan, H. Y. (1998). An analysis of inappropriate greetings and the strategies. Foreign Language Teaching and Research, 114, 28-31.

Liu, C. (2004). On the critical acceptance and application of Comprehensible Input Hypothesis. Journal of Beijing International Studies University, 102, 15-19.

Liu, H. Y., \& Li, Y. E. (1999). An investigation in the acceptance and refusal in interlanguage pragmatics. Foreign Language Teaching and Research, 115, 22-24.

Liu, P. (2018). Effects of Reading Task, Input Frequency and Lexical Item Type on Non-English Majors' Incidental Vocabulary Acquisition. Xi'an: Xi'an International Studies University.

Liu, Y. (2015). An empirical study on the development pattern of Chinese EFL learners' pragmatic competence. Foreign Language Research, 182, 114-119.

Long, M. (1983). Does second language instruction make a difference? A review of the research. TESOL Quarterly, 17, 359-382. https://doi.org/10.2307/3586253

Luo, Y. (2005). Frequency effects in Second Language Acquisition. Journal of Chongqing University (Social Science Edition), 11, 92-94.

Masaeed, K. A., Waugh, L. R., \& Burns, K. E. (2018). The development of interlanguage pragmatics in L2 Arabic: The production of apology strategies. System, 74, 98-108. https://doi.org/10.1016/j.system.2018.03.001

Niezgoda, K., \& Röver, C. (2001). Pragmatic and grammatical awareness: A function of learning environment. In K. Rose \& G. Kasper (Eds.), Pragmatics in Language Teaching. Cambridge: Cambridge University Press https://doi.org/10.1017/CBO9781139524797.008

Olshtain, E., \& Weinbach, L. (1993). Interlanguage features of the speech act of complaining. In G. Kasper \& S. Blum-Kulka (Eds.), Interlanguage Pragmatics. Oxford: Oxford University Press.

Ran, Y. P. (2013). Pragmatic considerations in research of English as a Lingua franca from a multi-contextual perspective. Foreign Language Teaching and Research, 45(5), 669-680, 798-799.

Ran, Y. P., \& Yang, Q. (2015). Re-conceptualization of ELF pragmatic competence with English as lingua franca. Foreign Language World, 5, 10-17.

Ran, Y. P., \& Yang, Q. (2016). Pragmatic competence in English as a lingua franca and its re-conceptualization. Foreign Language Teaching and Research, 48(2), 287-299, 321.

Sell, F., Renkwitz, K., Sickinger, P., \& Schneider, K. P. (2019). Measuring pragmatic competence on the functional and lexical level: The development of German high-school students' requests during a stay abroad in Canada. Journal of Pragmatics, 146, 106-120. https://doi.org/10.1016/j.pragma.2018.11.005

Shan, H., \& Liu, M. (2020). Strategies of college English listening and speaking teaching from the perspective of input and output hypothesis theory. Journal of Hubei Normal University (Philosophy and Social Science), 40, 119-123.

Shang, X. M. (1996). New-Griean theory of conversational implicature and foreign language teaching. Foreign Language Research, 85, 20-23. 
Shu, D. F. (2004). Problems and Suggested Solutions in Foreign Language Teaching Reform. Shanghai: Shanghai Foreign Language Education Press.

Sun, Y., \& Wang, D. W. (2003). Effects of input and output on oral competence development. Foreign Language World, 95, 31-35.

Tateyama, Y. (2001). Explicit and implicit teaching of pragmatic routines. In K. Rose \& G. Kasper (Eds.), Pragmatics in Language Teaching. Cambridge: Cambridge University Press. https://doi.org/10.1017/CBO9781139524797.015

Ting, Y. R. (2004). Second Language Acquisition for English Majors. Shanghai: Shanghai Foreign Language Education Press.

Weizman, E. (1993). Interlanguage requestive hints. In G. Kasper \& S. Blum-Kulka (Eds.), Interlanguage Pragmatics. Oxford: Oxford University Press.

Wen, Q. F. (2003). Success in English Learning. Shanghai: Shanghai foreign language education press.

Wen, Q. F. (2005). Frequency effects and second language acquisition: A review of SSLA (2002/6). Foreign Language Teaching and Research, 35, 151-154.

Wong, M. L.-Y. (2010). Expressions of gratitude by Hong Kong speakers of English: Research from the International Corpus of English in Hong Kong (ICE-HK). Journal of Pragmatics, 42, 1243-1257. https://doi.org/10.1016/j.pragma.2009.09.022

Wu, Y. Q., \& Chen, G. H. (2006). Chinese college students' pragmalinguistic competence: A survey and analysis. Foreign Languages in China, 1, 41-46.

Xiao, Y., \& Li, M. (2016). The effect of pragmatic input in the classroom on the development of pragmatic competence: an empirical study on Chinese tertiary-level learners of English. Shandong Foreign Language Teaching, 37(4), 49-55.

Xu, H. M. (1998). Input Theory and Foreign Language Learning. Journal of PLA University of Foreign Languages, 95, 7-13.

$\mathrm{Xu}, \mathrm{M}$. F. (2002). Optimizing input as to activate output: A reform on the audio-visual and speaking course. Technology Enhanced Foreign Language Education, 85, 3-7.

Yang, D. L., \& Li, M. Q. (2004). Probing into Input Theory. Foreign Language World, 99, 69-73.

Yang, S. Z. (1995). Developing pragmatic competence at the elementary state. Foreign language World, 59, 9-12.

Ye, S. N., \& Teng, Q. Y. (2003). Language teaching and the development of pragmatic competence. Foreign Language World, 98, 66-70.

Zhong, H., Fan, W. W., \& Qin, A. S. (2001). Research of non-English majors' social-cultural competence. Foreign Language World, 84, 19-23.

Zhou, C. M. (2013). Classroom teaching of EFL students' pragmatic competence. Journal of Southwest Agricultural University (Social Science Edition), 4, 110-113.

Zhou, D. D. (2004). Effects of task frequency on story retelling. Journal of PLA university of Foreign Languages, $27,41-45$.

Zhou, Z. Y., \& Shao, Y. C. (2003). Experimental study of pragmatic inference ability in English reading. Foreign Languages Research, 82, 57-61.

Zhu, M. J. (2000). Output and input in oral English teaching. Technology Enhanced Foreign Language Education, 77, 10-13.

Zhu, M. Q. (2000). Intensive reading of college English and the input of cultural background knowledge. Tongji University Journal (Social Science Section), 11(4), 81-83.

Zou, Q. (2019). Pragmatic strategies of requests used by Chinese business English learners in ELF. Journal of Hubei Polytechnic University (Humanities and Social Science), 36(4), 67-72. 


\section{Appendix A}

调 查 问 卷

姓名:

性别:

学号:

班级:

年龄:

学习英语年限:

A. Directions: For each dialogue, analyze whether the italicized parts are appropriate or not. Write "A" before the appropriate ones and "I" before the inappropriate ones. If you think the italicized parts are inappropriate, please write the appropriate expressions on the blank.

( ) 1) (in a bus) A: Excuse me. Is this seat taken?

B: I'm afraid this seat is taken.

A: Thank you very much.

( ) 2) Mrs. White: Please remember me to your family.

Tom: I'll do that.

( ) 3) A: Excuse me, please. (passing someone in a cinema)

B: Certainly.

4) A: Oh, you have had your hair permed (粱发)! It looks beautiful!

B: Thank you, do you really think so? I wasn't sure whether it suited me or not.

( ) 5) (in the students' dormitory) Andrew: Would you like to watch a football match?

Xiao Zhang: Excuse me, but I'm not free.

( ) 6) (One day, when an American lady accidentally bumped into Wei Lin)

Lady: I'm terribly sorry.

Wei: It doesn't matter.

( ) 7) (Joyce is talking to her friend, Brenda.)

Joyce: I wonder if you'd mind posting this letter for me on your way home, Brenda?

Brenda: I don't mind.

( ) 8) (One day, you went to see your American teacher, Kevin.)

Kevin: Would you like a cup of tea?

You: Yes, but I'm sorry to trouble you.

( ) 9) A: You look pale. What's the matter?

B: I'm feeling sick. A cold, maybe.

A: Go and see the doctor. Drink more water. Did you take any pills? Chinese medicine works wonderful. Would you like to try? Put on more clothes. Have a good rest.

（ ） 10） A: Is Carrefour (家乐福, 超市名) open Sundays?

B: Of course. 
( ) 11) (A is taking a cab, and he says to the driver)

A: Excuse me, would you mind taking me to the airport?

( ) 12) A: That's a lovely dress you've got!

B: Well, I went shopping on Saturday and happened to see it in one of the stores.

B. Directions: Please answer each of the following questions relating to the above 12 tasks, either in English or in Chinese, according to your own experience and opinions.

1) Have your English teachers ever told you in class how we should respond in the listed situations? If they have informed you of the appropriate behavior in some or all of the above situations, please list the item numbers below.

Answer:

2) Have you ever read anything about linguistic etiquette (礼节) in English? List the books/articles you probably have read.

Answer:

3) Do you often see English films? What do you care to know when you see English films?

Answer:

4) Do you think the knowledge of western linguistic etiquette necessary and important? Why or why not?

Answer:

---Thanks for Your Cooperation---

The tentative appropriate answers to the items in part A:

1) Thank you anyway.

2) Thank you. Sure I'll do.

3) Sorry.

4) Thank you. I'm glad you think so.

5) I'd love to. But I have a math test tomorrow morning.

6) It's fine.

7) No problem.

8) Yes. Thank you.

9) Take care.

10) Yes, it is.

11) airport, please.

12) Thank you. It's my favorite dress.

\section{Copyrights}

Copyright for this article is retained by the author, with first publication rights granted to the journal.

This is an open-access article distributed under the terms and conditions of the Creative Commons Attribution license (http://creativecommons.org/licenses/by/4.0/). 